\title{
Vitamin $\mathbf{K}_{\mathbf{1}}$ Increases Sister Chromatid Exchange in Vitro in Human Leukocytes and in Vivo in Fetal Sheep Cells: A Possible Role for "Vitamin $K$ Deficiency" in the Fetus
}

\author{
LYONEL G. ISRAELS, ELSA FRIESEN, ARNO H. JANSEN, AND ESTHER D. ISRAELS \\ Departments of Medicine and Pediatrics, University of Manitoba, the Manitoba Institute of Cell Biology and The \\ Manitoba Cancer Treatment and Research Foundation, Winnipeg, Manitoba, Canada
}

\begin{abstract}
The levels of the vitamin K-dependent clotting factors are markedly lower in the human fetus and newborn than in older infants and adults. Direct measurement of vitamin $K_{1}$ in cord plasma records low or undetectable levels. This phenomenon, although the norm, is referred to as vitamin $K$ deficiency and is a significant risk factor for hemorrhage in the fetus and newborn. Sister chromatid exchange (SCE), which may be used as an index of mutagenic activity, was assayed in cultured leukocytes of placental and adult blood following phytohemagglutinin stimulation. The mean number of SCES per metaphase in human placental blood was $3.32 \pm \mathrm{SE} 0.219$ as compared with levels of $5.13 \pm \mathrm{SE} 0.273$ in young adults $(p<0.01)$, and in the presence of added vitamin $K_{1}$ at a concentration of $1 \times 10^{-6} \mathrm{M}$ the SCE increased significantly in both adult and placental cells. In vitro SCE dose response curves to $K_{1}$ in the blood of fetal and maternal sheep were obtained. When five fetal sheep were given $1 \mathrm{mg}$ of $K_{1}$ by catheter into the femoral vein the SCE increased from 3.94 $\pm \mathrm{SE} 0.15$ preinjection to $5.38 \pm \mathrm{SE} 0.23$ at $24 \mathrm{~h}$ postinjection $(p<0.01)$. In the pretreatment fetal sheep, serum vitamin $K_{1}$ was below detectable levels in all seven animals in which it was assayed and reached levels as high as 0.3 $\times 10^{-6} \mathrm{M} 1 \mathrm{~h}$ post- $K_{1}$ injection. The low level of $K_{1}$ in the fetus may in fact confer some biological advantage by reducing the risk of mutagenic events during a period of rapid cell proliferation. (Pediatr Res 22: 405-408, 1987)
\end{abstract}

\section{Abbreviations}

SCE, sister chromatic exchange

BP, benzo(a)pyrene

MC, mitomycin C

MFO, mixed function oxidase

PHA, phytohemagglutinin

PT, prothrombin time

BrdV, bromodeoxymidine

HPLC, high-performance liquid chromatography

It would seem an anachronism that the newborn is either vitamin $\mathrm{K}$ deficient or in precarious vitamin $\mathrm{K}$ balance at birth. The low levels of the $\mathrm{K}$-dependent clotting factors place the newborn at some hemorrhagic risk. When bleeding does occur

Received February 12, 1987; accepted May 7, 1987

Correspondence and reprint requests Lyonel G. Israels, M.D., The Manitoba Cancer Treatment and Research Foundation, 100 Olivia Street, Winnipeg, Manitoba R3E 0V9, Canada. it responds to the injection of vitamin $\mathrm{K}$, and the coagulation factors rapidly approach adult levels. Direct measurement of $K_{1}$ confirms the low or undetectable levels in cord plasma, and the large concentration gradient between mother and fetus suggests that $K_{1}$ does not readily cross the placenta (1). The phenomenon of fetal and neonatal $\mathrm{K}$ deficiency is not confined to man or other mammals but also occurs in birds. In North America it is a standard practice to supplement the diet of newly hatched chicks with menadione (vitamin $\mathrm{K}_{3}$ ) as it is in most newborn nurseries to give parenteral $\mathrm{K}_{1}$ to newborns. Why are fetus and newborn placed at hemorrhagic risk - has nature made a mistake or does $\mathrm{K}$ deficiency confer some advantage during fetal life and early infancy in man and other species? Recent observations that vitamin $K_{1}$ accelerates BP tumorogenesis in mice (2) and that diet-induced $K_{1}$ deficiency in mice inhibits hepatic BP metabolite-DNA adduct formation in vivo (3) suggest that high or even "normal" levels of $\mathrm{K}_{1}$ may amplify potentially mutagenic or carcinogenic events. If so, higher levels would place the fetus and newborn at particular risk because of their high rates of cell proliferation.

To examine the problem more directly we studied the effect of vitamin $\mathrm{K}_{1}$ on SCE in leukocytes from human adult and cord blood. In addition, the response to the in vivo administration of $\mathrm{K}_{1}$, as monitored by SCE in leukocytes of fetal sheep, was determined.

\section{METHODS}

SCE in leukocytes was measured in the peripheral blood of 10 women between the ages of 21 and 43 and in blood obtained from the surface vessels of the placenta at the time of delivery or cesarean section of 10 normal full-term infants. We also assayed leukocytes from five fetal sheep between 130 and 135 days of gestation (full-term at 143 to 147 days) that weighed between 3.5 and $3.7 \mathrm{~kg}$. Twenty to $24 \mathrm{~h}$ before beginning the study a catheter was placed in the femoral vein to allow sampling and injection. Blood was obtained for SCE and PT. One $\mathrm{mg}$ of vitamin $\mathrm{K}_{1}$ (Konakion, Hoffman-La Roche) was injected and the sampling repeated 24 h later.

To measure the number of SCEs in human cells, lymphocytes were separated on a Ficoll-Hypaque gradient and $1 \times 10^{6} \mathrm{lym}-$ phocytes were added to $5 \mathrm{ml}$ of medium. Because of the small volumes available from the fetal sheep, whole blood was used and $0.4 \mathrm{ml}$ was added to $5 \mathrm{ml}$ of medium. The culture system was RPM 1 medium 1640 (GIBCO Labs) with added penicillin, streptomycin, and neomycin to which was added $12 \%$ by volume of fetal bovine serum (GIBCO Labs). This culture system contained no vitamin $\mathrm{K}$ but for the minor component present in fetal bovine serum. To this culture $0.1 \mathrm{ml}$ of PHA (Wellcome) was added at zero time and incubated at $37^{\circ} \mathrm{C}$ in $5 \% \mathrm{CO}_{2}$. At 
$24 \mathrm{~h} \mathrm{BrdU}, 6 \mu \mathrm{g} / \mathrm{ml}$, was added together with one of the following: 1) vitamin $K_{1}$ (2-methyl-3phytyl-1,4 naphthoquinone) (Sigma); 2) BP (Aldrich); 3) MC (Bristol); 4) acetone $6 \mu$, which was the solvent for all test compounds (control). Following another $48 \mathrm{~h}$ of incubation, Colcemid (Sigma), $0.05 \mu \mathrm{g} / \mathrm{ml}$ of medium, was added and incubation continued for an additional $2 \mathrm{~h}$. The lymphocytes were carefully protected from light during the entire incubation period. The cultures were centrifuged at low speed, the supernatant decanted and the red cells lysed in $0.075 \mathrm{M} \mathrm{KCl}$. The leukocytes were gently mixed and washed three times in methanol: glacial acetic acid $(3: 1)$, refrigerated overnight at $4^{\circ} \mathrm{C}$ and slides prepared with Hoechst 33258 and Giemsa according to the method of Perry and Wolff (4). Twentyfive metaphase spreads were examined in each sample by a single technician who was unaware of the prior treatment of each specimen.

The serum concentration of vitamin $\mathrm{K}_{1}$ was assayed by highperformance liquid chromatography on silica columns according to the method of Haroon and Hauschka (5) following the serum extraction procedure of Ueno and Suttie (6). The lower limit of vitamin $K_{1}$ detectable in serum was $0.5 \mathrm{ng} / \mathrm{ml}$. Prothrombin times were done on plasma from fetal sheep using human brain thromboplastin as the thromboplastic agent.

\section{RESULTS}

The mean numbers of SCEs in the separated lymphocytes from human adult female and from fetal placental blood are shown in Tables 1 and 2 . In Table 1 (adult) the in vitro incubation of lymphocytes with $\mathrm{K}_{1}, \mathrm{BP}$, and $\mathrm{MC}$ all produced a significant increase in SCE $(p<0.01)$ as compared with the controls. Both $\mathrm{BP}$ and MC produced significantly higher levels of SCE than did $\mathrm{K}_{1}(p<0.01)$. No difference was observed when $\mathrm{K}_{1}$ was added together with either BP or MC as compared with those agents alone. Similar findings and levels of significance were observed for placental blood (Table 2). In comparing adult (Table 1) with placental values (Table 2 ) there is a significantly lower level of SCE in placental blood (control) $(p<0.01)$ and in placental cells incubated in the presence of $\mathrm{K}_{1}(p<0.01)$. No significant differences were noted between the placental and adult values in the cells exposed to BP or MC.

The vitamin K-deficient status of the sheep fetus was established by PTs varying from 25 to $43 \mathrm{~s}$ which, $24 \mathrm{~h}$ after $\mathrm{K}_{1}$, had shortened to 16 to $23 \mathrm{~s}$. The PTs of the dams were between 14 and $16 \mathrm{~s}$. Figure 1 shows the in vitro dose response curve of sheep cells obtained at a single time point from a dam and her fetus. The SCE at a concentration of vitamin $K_{1}$ of $1 \times 10^{-10} \mathrm{M}$ was not different from the solvent control. As in the human the

Table 1. Mean number of exchanges per metaphase in cultured lymphocytes from young women*

\begin{tabular}{clccccc}
\hline Subject & Control & $\mathrm{K}_{1}$ & $\mathrm{BP}$ & $\mathrm{MC}$ & $\mathrm{K}_{1}+\mathrm{BP}$ & $\mathrm{K}_{1}+\mathrm{MC}$ \\
\hline 1 & 3.9 & 7.4 & 16.5 & 18.3 & 16.5 & 18.3 \\
2 & 4.2 & 6.0 & 16.9 & 18.9 & 16.7 & 17.2 \\
3 & 5.7 & 8.5 & 14.7 & 18.8 & 14.4 & \\
4 & 5.8 & 9.1 & 18.5 & 23.9 & 19.5 & 23.6 \\
5 & 5.0 & 8.6 & 17.0 & 24.1 & 17.3 & 20.1 \\
6 & 6.9 & 8.6 & 18.0 & 24.8 & 15.7 & 20.0 \\
7 & 5.0 & 7.6 & 17.0 & 20.1 & 17.4 & 20.4 \\
8 & 5.2 & 8.1 & 16.4 & 18.8 & 16.1 & 18.6 \\
9 & 5.1 & 8.0 & 17.3 & 26.0 & 17.1 & 21.2 \\
10 & 4.5 & 6.2 & 15.4 & 19.0 & 15.8 & 17.2 \\
& & & & & & \\
Mean & 5.13 & 7.81 & 16.77 & 21.27 & 16.65 & 19.62 \\
\pm SE & 0.273 & 0.326 & 0.354 & 0.960 & 0.426 & 0.685 \\
\hline
\end{tabular}

* Concentrations are: $\mathrm{K}_{1}, 1 \times 10^{-6} \mathrm{M} ; \mathrm{BP}, 1 \times 10^{-6} \mathrm{M} ; \mathrm{MC}, 1 \times 10^{-8}$ M. Comparisons of control vs treatment groups were done by Dunnetts many to one test (24). Multiple comparisons between treatment groups were done by Bonferroni matched pair analysis (25).
Table 2. Mean number of exchanges per metaphase in cultured lymphocytes from placental blood*

\begin{tabular}{ccccccc}
\hline Placenta & Control & $\mathrm{K}_{1}$ & $\mathrm{BP}$ & $\mathrm{MC}$ & $\mathrm{K}_{1}+\mathrm{BP}$ & $\mathrm{K}_{1}+\mathrm{MC}$ \\
\hline 1 & 2.4 & 4.7 & 14.6 & 17.2 & 14.5 & 15.7 \\
2 & 2.5 & 5.0 & 17.5 & 19.3 & 16.0 & 18.4 \\
3 & 2.9 & 5.2 & 12.2 & 14.6 & 13.4 & 14.6 \\
4 & 3.4 & 5.1 & 16.3 & 17.2 & 15.7 & 16.8 \\
5 & 3.0 & 7.4 & 16.7 & 18.5 & 15.3 & \\
6 & 3.8 & 6.6 & 16.8 & 20.7 & 16.4 & 16.4 \\
7 & 4.2 & 6.6 & 17.5 & 19.7 & 17.6 & 17.8 \\
8 & 3.0 & 5.3 & 15.1 & 15.2 & 14.3 & 14.7 \\
9 & 3.5 & 5.2 & 11.5 & 13.0 & & \\
10 & 4.5 & 6.5 & 16.8 & 20.6 & 14.3 & 20.5 \\
& & & & & & \\
Mean & 3.32 & 5.76 & 15.49 & 17.60 & 15.28 & 16.86 \\
ISE & 0.219 & 0.291 & 0.676 & 0.836 & 0.431 & 0.705 \\
\hline
\end{tabular}

${ }^{*}$ Concentrations are: $\mathrm{K}_{1}, 1 \times 10^{-6} \mathrm{M} ; \mathrm{BP}, 1 \times 10^{-6} \mathrm{M} ; \mathrm{MC}, 1 \times 10^{-8}$ M. Comparisons of control vs treatment groups were done by Dunnetts many to one test (24). Multiple comparisons between treatment groups were done by Bonferroni matched pair analysis (25).

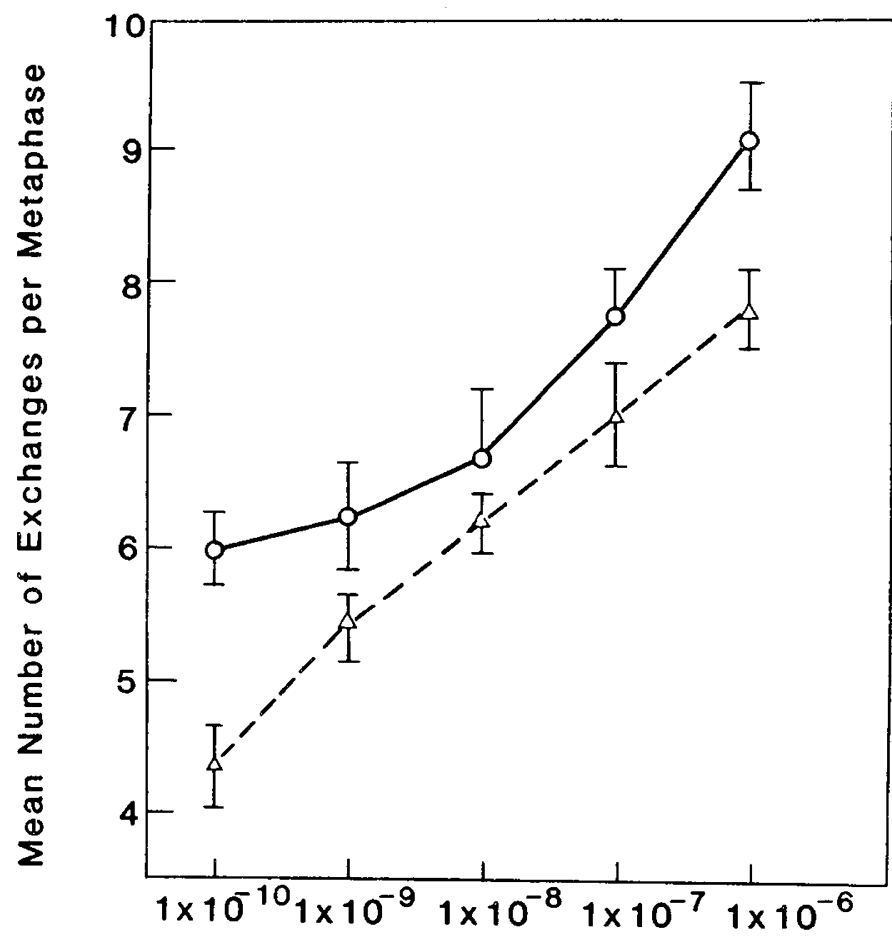

\section{Vitamin $K_{1}(M)$}

Fig. 1. Dose response curves (mean and SE of 25 observations per point) to increasing concentrations of $\mathrm{K}_{1}$ on leukocyte SCE in one dam $(\mathrm{O}-\mathrm{O})$ and her fetus $(\Delta-\Delta)$. The Kruskal-Wallis test $(26)$ and the Wilcoxon rank sum test (26) were applied in making comparisons between the concentrations of vitamin $\mathrm{K}_{1}$.

level of SCE is lower in the fetus. Both sets of observations increase with increasing concentrations of vitamin $K_{1}$ to a level of $1 \times 10^{-6} \mathrm{M}$. In analyzing the data from all individual mitoses at each concentration interval the increase observed at $1 \times 10^{-9}$ $\mathrm{M}$ as compared with $1 \times 10^{-10} \mathrm{M}$ in the fetus is significant $(p<$ $0.01)$. No significant increase in the dam occurred until a $K_{1}$ level of $1 \times 10^{-8} \mathrm{M}$ had been reached.

Table 3 documents the SCE in five fetal sheep before and 24 $h$ following the injection of $1 \mathrm{mg}$ of vitamin $K_{1}$. In each fetus the SCE was greater following $\mathrm{K}_{1}$ and, in the group considered as a whole, the mean preinjection level was $3.94 \pm$ SE 0.15 as 
Table 3. Mean number of exchanges per metaphase in fetal sheep leukocytes and serum $K_{1}$ levels before and $24 \mathrm{~h}$ after injection of $1 \mathrm{mg}$ of $K_{1}{ }^{*}$

\begin{tabular}{|c|c|c|c|c|}
\hline & Fetus & & SCE & $\mathrm{K}_{1}(\mathrm{ng} / \mathrm{ml})$ \\
\hline \multirow{2}{*}{\multicolumn{2}{|c|}{1}} & Pre $\mathrm{K}_{1}$ & 3.7 & $\mathrm{ND}+$ \\
\hline & & Post $\mathrm{K}_{1}$ & 5.8 & 9.1 \\
\hline \multirow{2}{*}{\multicolumn{2}{|c|}{2}} & Pre $\mathrm{K}_{1}$ & 3.5 & ND \\
\hline & & Post $\mathrm{K}_{1}$ & 4.7 & 7.1 \\
\hline \multirow{2}{*}{\multicolumn{2}{|c|}{3}} & Pre $K_{t}$ & 4.2 & ND \\
\hline & & Post $\mathrm{K}_{1}$ & 5.0 & 9.6 \\
\hline & 4 & Pre $\mathrm{K}_{1}$ & 4.3 & ND \\
\hline & & Post $\mathrm{K}_{1}$ & 5.9 & 10.6 \\
\hline & 5 & Pre $K_{1}$ & 4.0 & ND \\
\hline & & Post $\mathrm{K}_{1}$ & 5.5 & 24.8 \\
\hline Mean & & Pre & $3.94 \pm 0.15$ & ND \\
\hline$\pm \mathrm{SE}$ & & Post & $5.38 \pm 0.23$ & $12.24 \pm 3.19$ \\
\hline
\end{tabular}

* Significance pre versus post $p<0.01$. Paired $t$ tests using Bonferroni $t$ statistics (25) are applied to test for pre versus post differences in each group.

$\uparrow$ Not detectable.

compared with $5.38 \pm \operatorname{SE} 0.2324$ h following $\mathrm{K}_{1}(p<0.01)$. When cells obtained preinjection were incubated in vitro with $\mathrm{K}_{1}\left(1 \times 10^{-6} \mathrm{M}\right)$ the SCE increased to $6.0 \pm \mathrm{SE} 0.62$ as compared to the control of $3.94 \pm \operatorname{SE~} 0.15(p<0.01)$. However, there was no further increase found on in vitro incubation with $\mathrm{K}_{1}(1 \times$ $10^{-6} \mathrm{M}$ ) of postinjection cells.

Table 3 also records the levels of serum $K_{1}$ assayed before and $24 \mathrm{~h}$ after the injection of $1 \mathrm{mg}$ of $\mathrm{K}_{1}$. In no fetus was $K_{1}$ detectable in the preinjection sample. Twenty-four $\mathrm{h}$ after the injection of $1 \mathrm{mg}$ of $K_{1}$ the levels ranged from 7.1 to $24.8 \mathrm{ng} /$ $\mathrm{ml}$. In two fetal sheep in which sera were assayed before and $1 \mathrm{~h}$ after the intravenous injection of $1 \mathrm{mg}$ of $\mathrm{K}_{1}$ the levels were nondetectable preinjection and were 142.7 and $57.2 \mathrm{ng} / \mathrm{ml} 1 \mathrm{~h}$ after injection.

\section{DISCUSSION}

In 1969 the following appeared as an editorial footnote: "We believe that the weight of evidence-clearly indicates the benefits to be derived from the routine administration at the time of delivery of a small dose of vitamin $\mathrm{K}$ to all newborn infants. There seems to be no justification whatsoever for withholding this preparation and we would earnestly hope that the subject will not be reopened for at least another 10 years. Twenty years would be even better" (7). Although this practice is now almost routine in North America the basis of this regimen is still questioned elsewhere (8). The controversy arises in part from the fact that we are intervening in a natural phenomenon. Why the normal newborn reaches the outside world in a state requiring immediate supplementation with an essential vitamin has not been explained.

That the vitamin $\mathrm{K}$-dependent coagulation factors are low in the fetus and newborn and that bleeding may occur and is corrected or prevented by vitamin $\mathrm{K}$ is firmly established. Hemorrhagic disease of the newborn on this basis may occur within the first few days of life or, in solely or mainly breast-fed babies, as late as 4 to $8 \mathrm{wk}$ after birth. Direct measurement of vitamin $\mathrm{K}_{1}$ in plasma by HPLC records levels in fasting adults from 0.10 to $0.66 \mathrm{ng} / \mathrm{ml}$ but $\mathrm{K}_{1}$ was not detectable by this method in cord plasma (1). Although the low levels of $\mathrm{K}$, either measured directly or inferred by the low levels of the $\mathrm{K}$-dependent clotting factors, is the norm in the human fetus and in other species, it is common to refer to this state as "vitamin K deficiency." Is it not possible that this level of vitamin $\mathrm{K}$ provides an advantage to the embryo or fetus which compensates for the neonatal risk? The present findings suggest that these lower levels of $\mathrm{K}$ may in fact confer some advantage on the rapidly growing fetus.
SCE represents the interchange of DNA at homologous chromosomal loci and is dependent on both chromosomal breakage and repair. Although there is not perfect agreement between the ability of a compound to produce SCE and its mutagenicity or carcinogenicity there is a high degree of correlation (9). Some known carcinogens such as diethylstibesterol are detected by SCE although found to be negative in the Salmonella assay $(10,11)$. Although vitamin $K_{1}$ was not mutagenic in Salmonella strains TA98, TA100, or TA2637 (12), the demonstration that $\mathrm{K}_{1}$ supplementation increased SCE at a concentration of $1 \times 10^{-6}$ $M$ in vitro and at a dose of $1 \mathrm{mg}$ in vivo must be considered a significant chromosomal event.

In the present studies of human leukocytes the level of SCE was significantly lower in cord cells than in those of normal adults (Tables 1 and 2). A higher frequency of SCE in adults than in children (ages 0.2 to $4.5 \mathrm{yr}$ ) has been observed and was postulated to be on the basis of continuing exposure to environmental mutagenic agents (13). SCE in fetal cells was found to be less than in maternal marrow cells in C57BL/6J mice prior to mutagenic exposure (14). In both adult and fetal leukocytes, in vitro incubation with $\mathrm{K}_{1}$ at a concentration of $1 \times 10^{-6} \mathrm{M}$ induced a significant increase in exchanges although much less than the classical mutagens BP and MC. That the in vitro effect of $\mathrm{K}_{1}$ was not additive to that of $\mathrm{BP}$ and $\mathrm{MC}$ may indicate that the exchanges induced by $K_{1}$ are occurring at some of the same chromosomal sites as those produced by BP and MC. Exchange is not a random event and certain chromosomal regions are preferential sites of high exchange frequency (15).

Figure 1 shows the SCE dose response curves to $K_{1}$ in the leukocytes of a dam and her fetus. As in the human the control values $\left(\mathrm{K}_{1}\right.$ at $\left.1 \times 10^{-10} \mathrm{M}\right)$ in the fetus are less than in the mother. Both maternal and fetal SCE levels increase with increasing concentration of $\mathrm{K}_{1}$ but the fetus responds significantly at lower concentrations of $\mathrm{K}_{1}$. This may relate to the higher concentration of $\mathrm{K}_{1}$ in maternal plasma so that the effect of the addition of $K_{1}$ at concentrations below $1 \times 10^{-8} \mathrm{M}$ is diluted out by the $\mathrm{K}_{1}$ normally present. The in vivo injection of $1 \mathrm{mg}$ of $\mathrm{K}_{1}$ to the fetus produces a significant increase in SCE. This dose of $\mathrm{K}_{1}$ is equivalent to that recommended for full-term human newborns of comparable weight.

The vitamin $\mathrm{K}_{1}$ level in each fetus was below the level of detection of the assay $(<0.5 \mathrm{ng} / \mathrm{ml})$. In all fetal sheep $\mathrm{K}_{1}$ was easily measurable $24 \mathrm{~h}$ after the intravenous injection of $1 \mathrm{mg}$ of $\mathrm{K}_{1}$ and ranged from 7.1 to $24.8 \mathrm{ng} / \mathrm{ml}$. In two other fetal sheep in which serum $K_{1}$ was assayed $1 \mathrm{~h}$ postinjection these levels were 142.7 and $57.2 \mathrm{ng} / \mathrm{ml}$. These levels are well above those required to produce SCE in fetal sheep cells in vitro (Fig. 1).

It is significant that in the human adult the total body pool, excluding ingested and bacterial vitamin $\mathrm{K}$ in the gut, is extremely small. Bjornsson et al. (16) estimated the turnover time of intravenously administered vitamin $\mathrm{K}_{1}$ to be $153 \mathrm{~min}$ and the body pool to be replaced every $2.5 \mathrm{~h}$. Duello and Matschiner's (17) data suggest the hepatic pool, which is the primary site of $\mathrm{K}_{1}$ storage, to be about $300 \mu \mathrm{g}$. Although multiple forms of menaquinones $\left(\mathrm{K}_{2}\right)$ are also present in the hepatic pool (17) it is not an uncommon clinical observation in patients deprived of oral intake and placed on broad-spectrum antibiotics that the vitamin K-dependent clotting factors frequently fall within 6 to 7 days which, when the half-lives of the factors are considered, indicates that $\mathrm{K}$ depletion occurs within 72 to $96 \mathrm{~h}$. This has been documented in a series of case reports $(18,19)$.

In addition to the direct chromosomal effects demonstrated in this study, it has previously been shown, in a microsomal system, that low concentrations of $\mathrm{K}_{1}$ may increase the MFO metabolism of the procarcinogen BP to more proximate carcinogenic metabolites (3). The MFO system mediates the metabolism of a number of hydrophobic organic molecules including the polycylic hydrocarbons such as BP. The initial (phase I) reaction produces primary and secondary metabolites which are frequently more toxic or mutagenic than the parent compound. These are then 
conjugated (phase II) with glutathione, glucuronic acid, or sulfate prior to excretion (20). In the vitamin K-deficient chick embryo system, the in vivo administration of $\mathrm{K}_{1}$ augments BP metabolism (phase I) with a concomitant decrease in at least one phase II pathway suggesting that $K_{1}$ could assume an adjuvant role in mutagenicity in this embryo system (21). If $\mathrm{K}_{1}$ at levels marginally above those present in vivo modulates MFO metabolism to enhance production of potentially toxic, mutagenic, or carcinogenic metabolites, then maintaining $\mathrm{K}_{1}$ at a cellular concentration only sufficient to meet the immediate needs of the $\gamma$ carboxylase system and without cellular excess is a biological advantage. This is particularly so in the fetus which, although it has an active and inducible MFO system (22), has a much reduced capacity for the conjugation and excretion of such metabolic products. Conjugation with glucuronic acid is one such pathway and glucuronyl transferase activity is only $20 \%$ of the adult levels at birth although it rapidly increases to reach adult levels by 2 to 4 days postpartum (23).

These findings do not negate the use of therapeutic or prophylactic vitamin $K_{1}$ in the newborn. Hemorrhagic disease of the newborn may be fatal or leave the infant with devastating disability. However, it is necessary to reconsider the phenomenon of "vitamin K deficiency," which is the norm for this period of growth and development, in terms of the role it may play in the protection of the fetus in utero.

Acknowledgments. The authors thank Drs. V. Chernick, M. Ray, and B. Nayak for their advice and expertise and to Karam Ramotar for the vitamin $K_{1}$ assays. Drs. N. Nelson and P. Moodie of the section of Epidemiology and Statistics performed the statistical analysis.

\section{REFERENCES}

1. Shearer MJ, Barkhan P, Rahmin S, Stimmler L 1982 Plasma vitamin $K_{1}$ in mothers and their newborn babies. Lancet 2:460-463

2. Israels LG, Walls GA, Ollmann DJ, Friesen E, Israels ED 1983 Vitamin K as a regulator of benzo(a)pyrene metabolism, mutagenesis, and carcinogenesis. J Clin Invest 71:1130-1140

3. Israels LG, Ollmann DJ, Israels ED 1985 Vitamin $K_{1}$ as a modulator of benzo(a)pyrene metabolism as measured by in vitro metabolite formation and in vivo DNA-adduct formation. Int J Biochem 17:1263-1266

4. Perry P, Wolff S 1974 New Giemsa method for the differential staining of sister chromatids. Nature 251:156-158
5. Haroon Y, Hauschka PV, 1983 Application of high-performance liquid chromatography to assay phylloquinone (vitamin $\mathrm{K}_{1}$ ) in rat liver. $\mathbf{J}$ Lipid Res $24: 481-485$

6. Ueno T, Suttie JW 1983 High-pressure liquid chromatographic reductive electrochemical detection analysis of serum trans-phylloquinone. Anal Biochem 133:62-67

7. Editors Note 1969 The Year Book of Pediatrics. Year Book Medical Publishers, Chicago

8. Kunzer W, Niederhoff $H$, Pancochar H, Sutor AH 1983 Das neugeborene und vitamin K. Dtsch Med Wochenschr 108:1623-1624

9. Latt SA, Schreck RR, Loveday KS, Dougherty CP, Shuler CF 1980 Sister chromatid exchanges. Adv Hum Genet 10:267-331

10. Wolff $S 1983$ Sister chromatid exchange as a test for mutagenic carcinogens. Ann NY Acad Sci 407:142-153

11. Glatt HR, Metzler M, Oesch F 1979 Diethylstilbesterol and 11 derivatives: a mutagenicity study with Salmonella typhimurium. Mutat Res 67:113-121

12. Tikkanen L, Matsushima T, Natori S, Yoshihira K 1983 Mutagenicity of natural naphthoquinones and benzoquinones in the Salmonella/microsome test. Mutat Res 124:25-34

13. Funes-Cravioto F, Kolmodin-Hedman B, Lindsten J, Nordenskjold M, ZapataGayon C, Lambert B, Norberg E, Olin R, Swenson A 1977 Chromosome abberations and sister-chromatid exchange in workers in chemical laboratories and a rotoprinting factory and in children of women laboratory workers. Lancet 2:322-328

14. Kram D, Bynum GD, Senula GC, Schneider EL 1979 In utero sister chromatid exchange analysis for detection of transplacental mutagens. Nature 279:531

15. Latt SA, Juergens LA 1976 Determinants of sister chromatid exchange frequencies in human chromosomes. In: Hood EB, Porter I (ed) Population Cytogenetics. Academic Press, New York, pp 217-236

16. Bjornsson TD, Meffin PJ, Swezey SE, Blaschke TF 1979 Effects of clofibrate and warfarin alone and in combination on the disposition of vitamin $K_{1} . J$ Pharmacol Exp Ther 210:322-326

17. Duello TJ, Matschiner JT 1972 Characterization of vitamin K from human liver. J Nutr 102:331-335

18. Pineo GF, Gallus AS, Hirsh J 1973 Unexpected vitamin K deficiency in hospitalized patients. Can Med Assoc J 109:880-883

19. Pakter RL, Russell TR, Miekle CH, West D 1982 Coagulopathy associated with use of moxalactam. JAMA 248:1100

20. Gelboin HV, 1980 Benzo(a)pyrene metabolism, activation and carcinogenesis: role and regulation of mixed-function oxidases and related enzymes. Physiol Rev 60:1107-1166

21. Dogra SC, Israels LG 1987 Vitamin $K_{1}$ amplification of benzo(a)pyrene metabolism in chick embryos. Int J Biochem 19:471-473

22. Oesch F 1980 Influence of foreign compounds on formation and disposition of reactive metabolites. Ciba Found Symp 76:169-189

23. Thaler M 1972 Perinatal bilirubin metabolism. Advan Pediatr 19:215-235

24. Dunnett CW 1964 New tables for multiple comparisons with a control. Biometrics 20:482-491

25. Miller RG Jr 1981 Normal univariate techniques. In: Simultaneous Statistical Inference. Springer Verlag, New York, pp 67-70

26. Sokal R, Rohlf FJ 1981 Assumption of analysis of variance. In: Biometry. WH Freeman, San Francisco, pp 429-437 